\title{
Re-visiting the role of intra-partum cardio-tocography (I-P CTG) in cerebral palsy jurisprudence: Time to take cognizance
}

\author{
George Gregory Buttigieg ${ }^{1 *}$ and Kirill Micallef Stafrace ${ }^{2}$ \\ ${ }^{1}$ University of Malta, Msida MSD 2080, Malta \\ ${ }^{2}$ University of Malta, Msida MSD 2080, Malta
}

\begin{abstract}
Both clinical obstetrics as well the relevant medico-legal litigation was severely let down by false scientific conclusions emanating from the USA in the 1960's. The false assumptions considered birth asphyxia as the predominant cause of new-born Cerebral Palsy and proclaimed the just introduced fetal cardio-tocography (CTG), as the great saviour from CP through the detection of intra-partum hypoxia. Although today, fifty odd years later, science admits that neither conclusion is correct, CTG has retained its misplaced strength in CP litigation. Not only does it still hold much pre-eminence in both UK and US jurisprudence, but sometimes, it constitutes the sole basis of discussion.

The only scientifically valid and practical way of correction is the recognition that CP due to intra-partum hypoxia has the underlying hallmark pathology of Hypoxic Ischaemic Encephalopathy (HIE). This constitutes no more than $20 \%$ of CP. Other aspects of obstetric care, including in the antenatal period may have a basis for alleging negligence, but CP due to peri-partum hypoxia must be accompanied by HIE. The 2003/2014 criteria for diagnosing HIE were established by the American College of Obstetricians in liaison with the American Academy of Paediatricians. This provides a reliable guide to the diagnosis by integrating clinical obstetrics/ neonatology/midwifery observations, fetal/ newborn biochemical data, newborn cerebral MRI/ MRI spectroscopy imaging, and evidence of fetal multisystem organ failure. These must be the new parameters on which CP jurisprudence should be justly and scientifically based.
\end{abstract}

\section{Introduction}

In cases alleging medical negligence as a cause of Cerebral Palsy, it is still the general rule that Cardio-tocographic (CTG) analysis is the brunt of evidence brought forward by the plaintiff, in both UK and USA. Furthermore, it is not unusual for intra-partum CTG (I-P CTG) analysis, with or without fetal acid-base confirmation of fetal distress, to be the sole evidence, on which the defendant's fate is determined. While accepting that intra-partum CTG evidence is essentially the only parameter of assessing fetal response to the stress of labour, the extrapolation of this investigation as the sole medico-legal evidence of negligence as causative of Cerebral Palsy, is no longer tenable [1]. Although not directly relevant to the validity of this statement, one should also bear in mind that Cerebral Palsy constitutes $60-70 \%$ of the total yearly malpractice sum paid by the UK NHS Litigation Authority [2].

\section{Hypoxic ischaemic encephalopathy}

I-P CTG, by itself, cannot establish a diagnosis of fetal hypoxia and acidosis. Even in a bad case scenario, an abnormal I-P CTG tracing, the incidence of fetal hypoxaemia and acidosis can be confirmed in only 50 $60 \%$ of cases [3]. Here, we shall not dwell on the myriad pitfalls of I-P CTG interpretation such as intra- and inter-observational errors, CTG nomenclature limitations, CTG's high specificity and low sensitivity... leading to the "shifting sands phenomenon" of this ubiquitously used investigation. However, an abnormal I-P CTG tracing is an indication for confirming or negating intra-uterine hypoxia such as by Fetal Blood Sampling (FBS), with or without one of the more modern methods such as STAN.
The crucial question is whether the fetal hypoxia and subsequent acid-base disturbance was severe enough to cause Hypoxic Ischaemic Encephalopathy (HIE), the underlying cerebral lesion contributing to the estimated $20 \%$ of Cerebral Palsy caused at birth $(70 \%$ are due to prenatal causes and about $10 \%$ by post-natal causes). Although liability through negligence may also operate antenatally e.g. a mismanaged chorio-amnionitis, the discussion at hand, centres on alleged negligence in labour with resultant fetal hypoxia. In fact, one may surmise that the vacuum caused by the diminution of alleged labour mismanagement as based on unjustified I-PCTG analysis, will eventually shift onto justifiable ante-natal management scrutiny. However, sticking with the facts here, any intra-partum hypoxia proved to be present by acid-base/ STAN confirmation of I-P CTG tracing abnormality must be shown to have induced HIE. This should be the crux of the basis medico-legal argumentation alleging negligence. And how does one show this, clinically and in a practical way for the Courts to analyse and reflect upon?

\section{The ACOG as light bearer}

It was in the 1960's, that the cause of Cerebral Palsy in general was wrongly honed on labour and on the fact that oxygen deprivation was the cause. We now know that this is the cause of the great minority of cases, but the damage was done and is still operative today. Pre-1970 related malpractice claims were few [4], but by 1985, they comprised

Correspondence to: George Gregory Buttigieg, University of Malta, Msida MSD 2080, Malta, E-mail: George.g.buttigieg@um.edu.mt

Received: December 05, 2017; Accepted: December 20, 2017; Published: January 04, 2018 
$10 \%$ of all medical malpractice lawsuits [5]. As yet, all studies have shown that in spite of universal use of I-P CTG monitoring, Cerebral Palsy incidence has not been diminished. To quote a recent study:

Consequently, there is a lack of confidence, marked variation in FHR interpretation, defensive practices, unnecessary operative interventions, and a failure to recognise abnormal FHR patterns, resulting in adverse outcomes and expensive litigation [6].

However, it was also the USA, through the American College of Obstetricians and Gynaecologists, in conjunction with the American Academy of Paediatrics (AAP) which has been the first to rectify the original misconceptions. For, although not addressing the medicolegal aspect directly, the ACOG, through its Task Force Report of 2003 [7], and as further amended in 2014 [8], has shed the first logical guidance to the establishment of HIE. By the creation of a core group and a secondary group of criteria it correlated clinical, neurological, biochemical, neuroimaging evidence of cerebral hypoxic ischaemia as well as similar evidence of damage in other organs in a logical and scientific basis to establish the evidence of the presence HIE.

\section{The significance and implication of the ACOG-AAP criteria on present Cerebral Palsy jurisprudence}

It is most medico-legally instructive that the principal or core criteria of the ACOG classification does not even include I-P CTG. It includes:

1. Apgar score of less than 5 at 5 minutes and 10 minutes.

2. Fetal umbilical artery $\mathrm{pH}$ less than 7.0 , or base deficit greater than or equal to $12 \mathrm{mmol} / \mathrm{L}$, or both.

3. Neuroimaging evidence of acute brain injury seen on brain magnetic resonance imaging or magnetic resonance spectroscopy consistent with hypoxia-ischemia.

4. The presence of multisystem organ failure consistent with hypoxicischemic encephalopathy.

The second group includes CTG among other parameters. The message is loud and clear. It is also simple and brilliant in that the scope of I-P CTG is the detection of fetal hypoxia - the ACOG HIE criteria demand evidence of such hypoxia - biochemical, through neuroimaging and by the presence of organ failure resulting from hypoxia. CTG monitoring has not been displaced from its key monitoring position in cases of high risk labour. But its role as key factor in establishing an underlying link to Cerebral Palsy through HIE has been put in its correct pecking order.

On reflecting on the significance of this ACOG- AAP Classification, the paltry value of I-P CTG jurisprudence purely based on plaintiffdefendant squabbles on early or late decelerations, variability... becomes clear.

\section{Light at the end of the tunnel}

If the march of science is a slow one, that of medico-legal practice is even slower. It has taken close to 60 years for the Bolam test to be toppled (and that only as regards disclosure of information) by the House of Lords in Nadine Montgomery Appellant against Lanarkshire Health Board Respondent, even though it had been overtly challenged before, as in Rogers $v$ Whitaker. The ACOG HIE criteria classification and its application to Cerebral Palsy litigation is unlikely to hit home any time soon. Yet one does take heart on perusal of contemporary case law.
In AW Pursuer against Greater Glasgow Health Board Defenders [29], we find a UK case about alleged medical negligence leading to Cerebral Palsy. The argumentation was for from being I-P CTG oriented, comprising as it did thirteen experts from obstetrics, midwifery, biochemistry, neuro-radiology, neurology and neonatology. The ACOG -AAP criteria were not referred to by name, but it was there in spirit. This is the right and fair, unequivocal and all - encompassing way forward for justice to prevail in Cerebral Palsy Jurisprudence.

It is indeed encouraging to conclude with this case, which is showing the right way forward. The approach is a more expensive one, involving several multi-disciplinary experts and much challenging counter-argumentation with its experts from both the plaintiff and the defendant. Anyone who presents a Court case, pleading liability for a case of Cerebral Palsy, solely based on a I-P CTG tracing is seeking a wrong and utterly delusional situation. Several such cases exist and have been thrown out of Court on the grounds that liability has not been proven. The light of day will certainly dawn with the first case that the Jurisprudential reason stated by the bench will be that in view of firmly established facts by modern medical science, CTG-oriented legal argumentation in a case of CP does not even begin to produce evidence based on the requisite criteria. Only then will the penny drop. Furthermore such an approach will save money all round as well as the Court's precious time.

This communication is fully aware that a paradigm shift is here being proposed in $\mathrm{CP}$ litigation. And this shift only involves the Courts in the last and most dramatic of scenarios, namely the Court battle. For, cases of neonatal Cerebral Palsy demand, as a bare minimum, the results of the clinical parameters in the principal or core criteria group of the 2003/2014 RCOG Task Force recommendations as routine practice. This includes the Apgar score, fetal umbilical artery $\mathrm{pH}$ and acid base balance, neonatal neuro-imaging on MRI or magnetic resonance spectroscopy and the corresponding investigations to rule out or confirm multi-sysytem organ failure. Needless to say, the I-P CTG will also be there - but certainly not among the first-line evidence. CTG argumentation may, offer, its own contribution, for example in a retrospective analysis of the timing of incidents of the intra-partum obstetric management. This is a far cry from the present scenario. It is also a loud and indispensable cry, seeking justice in this type of Jurisprudence, where compensation, not unusually, runs in the millions, be it American dollars or English sterling.

\section{References}

1. Buttigieg GG (2017) Lessons from the Great Medico-Legal Chapter of Cerebral Palsy. J Neurol Disord 5: 335.

2. Ten Years of Maternity Claims An Analysis of NHS Litigation Authority Data. NHS Litigation Authority October 2012

3. Hinshaw K, Ullal A (2007) Peripartum and intra-partum assessment of the fetus Anaesthesia \& Intensive Care Medicine 8: 331-336.

4. Cerebral Palsy Fact Sheet (2017) United Cerebral Palsy. Accessed on 23 March 2017.

5. DeVille KA (1990) Medical Malpractice in Nineteenth Century America: Origins and Legacy. New York, NY: New York University Press.

6. Ugwamadu A (2014) Are we (mis)guided by current guidelines on intrapartum feta heart rate monitoring? Case for a more physiological approach to interpretation. BJOG. 2014 Aug;121(9):1063-70.

7. The American College of Obstetricians and Gynecologists' Task Force (2003) Neonatal encephalopathy and cerebral palsy, The American College of Obstetricians and Gynecologists, the American Academy of Pediatrics.Neonatal encephalopathy and cerebral palsy: Defining the pathogenesis and pathophysiology. Washington, DC: The American College of Obstetricians and Gynecologists. 2003: 1-85. 
Buttigieg GG (2018) Re-visiting the role of intra-partum cardio-tocography (I-P CTG) in cerebral palsy jurisprudence: Time to take cognizance

8. ACOG Executive Summary (2014) Neonatal encephalopathy and neurologic outcome. ( $2^{\text {nd }}$ edn). Obstetrics and Gynecology 123: 896-901.

9. Nadine Montgomery Appellant against Lanarkshire Health Board Respondent -2015 S.C.C.L.R. 315
10. Rogers $v$ Whitaker (1992) 175 CLR 479.

11. AW Pursuer against Greater Glasgow Health Board Defenders. CSOH 99 (2015)

Copyright: (C2017 Buttigieg GG. This is an open-access article distributed under the terms of the Creative Commons Attribution License, which permits unrestricted use, distribution, and reproduction in any medium, provided the original author and source are credited. 